\title{
Circulating DBP level and prognosis in operated lung cancer: an exploration of pathophysiology
}

\author{
Alice M. Turner*, Laura McGowan*, Alan Millen\#, Pala Rajesh", Craig Webster", \\ Gerald Langman ${ }^{\#}$, Gavin Rock*, Isao Tachibana", Michael G. Tomlinson+, \\ Fedor Berditchevski ${ }^{\S}$ and Babu Naidu ${ }^{f}$
}

ABSTRACT: Vitamin D stimulates transcription of antiangiogenic and apoptotic factors that may suppress tumours, while vitamin D binding protein (DBP) may be a biomarker in murine lung cancer models. We sought to ascertain whether the vitamin $D$ axis is altered in lung cancer or influences prognosis.

148 lung cancer patients, 68 other intrathoracic cancer patients and 33 noncancer controls were studied for up to 5 yrs. Circulating DBP and vitamin D levels were compared between groups and their effect on survival assessed by Cox regression analysis. Expression of DBP and vitamin D receptor (VDR) was examined in lung cancer cell lines and in normal and tumour lung tissue by Western blot and immunohistochemistry.

Low serum DBP levels predicted lung cancer-specific death $(p=0.04)$, and DBP was poorly expressed in lung cancer cells on Western blot and immunohistochemistry. Vitamin D did not predict cancer survival and VDR expression was variable in tumours.

Preservation of serum DBP is a significant independent factor associated with better cancer outcome in operated lung cancer patients. Given the established role of DBP in macrophage activation and clearance of abnormal cells, further study on its involvement in lung cancer is merited.

KEYWORDS: Epidemiology, lung cancer, prognosis, vitamin D

$\mathbf{V}$ itamin $\mathrm{D}$ is a fat-soluble vitamin best known for its role in calcium and phosphate homeostasis. It is also increasingly apparent that vitamin $\mathrm{D}$ has beneficial health effects beyond the skeletal system. Serum concentration of cholecalciferol (vitamin $\mathrm{D}_{3}$ ) as 25-hydroxycholecalciferol $\left(25 \mathrm{OHD}_{3}\right)$ is the best indicator of vitamin $\mathrm{D}$ status as it reflects cutaneous production as well as that intake in foods and supplements, whereas 1,25 -dihydroxycholecalciferol $\left(1,25(\mathrm{OH})_{2} \mathrm{D}_{3}\right)$ has a short half-life and serum concentrations are tightly regulated [1]. Vitamin D status has been reported to correlate with cancer risk, and play a role in the prevention of colon, prostate and breast cancers [2], although less is known about its influence on lung cancer. None of the available epidemiological work has been able to determine the level of risk conferred by vitamin D deficiency, because of confounders such as obesity and amount of sunlight exposure.
Vitamin D may suppress tumour progression by reducing cell proliferation, invasiveness and angiogenesis, and stimulating apoptosis [2-4]. It also protects against metastases in various tumour models, including the lung [2-4]. In order for vitamin D to exert its intracellular effects, it must enter cells by diffusion or by endocytosis when bound to its main carrier protein, vitamin D binding protein (DBP). Once inside the cell, vitamin $\mathrm{D}$ dissociates from DBP and then undergoes a series of reactions that enable interaction with the vitamin D receptor (VDR), a process illustrated in our previous work [5]. There is some suggestion that VDR expression is reduced in lung cancer [6], implying that vitamin $\mathrm{D}$ will be less able to exert its antitumour effects, such that other aspects of the vitamin $\mathrm{D}$ axis could be more important.

DBP is a glycosylated $\alpha$-globulin, part of the albumin superfamily, being $\sim 58 \mathrm{kDa}$ in size,
AFFILIATIONS

*School of Clinical and Experimental Medicine, University of Birmingham, +School of Biosciences, University of Birmingham,

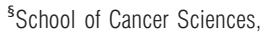
University of Birmingham,

"Birmingham Heartlands Hospital, Heart of England NHS Foundation Trust, Birmingham, and ${ }^{f}$ Warwick Medical School, University of Warwick, Coventry, UK. "Dept of Respiratory Medicine, Allergy and Rheumatic Diseases, Osaka University Graduate School of Medicine, Osaka, Japan.

CORRESPONDENCE

B Naidu

Warwick Medical School

University of Warwick

Coventry

CV4 7AL

UK

E-mail: u.b.naidu@warwick.ac.uk

Received:

Jan 062012

Accepted after revision:

April 142012

First published online:

May 032012 
produced in the liver and located predominantly in serum. It is divided into two large domains (I and II) and a shorter domain at the carboxyl terminus (domain III) [7], and is expressed in many tissues [8] and by neutrophils [9]. It contributes to macrophage activation [10], augments monocyte and neutrophil chemotaxis to C5-derived peptides, and acts as an actin scavenger protein, as discussed in our recent review [5]. It may play a role in malignancy because of its effect on macrophages, which are important because of their potential to clear abnormal tissue [11]. Indeed, in lung cancer, the number of cytotoxic macrophages within the tumour predicts survival [12]. The vitamin D axis may optimise antitumour actions of macrophages in two ways. First, DBP can be converted by deglycosylation into a potent macrophage activating factor (MAF) [10]. Thus, in tissue where DBP is poorly expressed or poorly converted to DBP-MAF, macrophage activation will be suboptimal. Little is known about DBP expression in lung tissue, although we have demonstrated previously that DBP is present in airway secretions [13]. Secondly, macrophages can convert $25 \mathrm{OHD}_{3}$ to $1,25(\mathrm{OH})_{2} \mathrm{D}_{3}$ [14], thus optimising downstream effects on antitumour gene transcription in these cells.

We hypothesised that the vitamin D axis may be altered in lung cancer and relate adversely to prognosis: this may be due to either vitamin D deficiency, inability of tumour tissue to respond to vitamin $\mathrm{D}$, or reduced macrophage activation by DBP-MAF in and around tumours.

\section{METHODS}

\section{Prognostic effect of serum markers of the vitamin $D$ axis}

Patients were recruited consecutively from thoracic surgery lists at the Heart of England NHS Foundation Trust (HEFT) between 2006 and 2009. Serum samples were taken at several time points, as part of the CLUB (Carcinoma of the Lung Biomarkers) study, a prospective study of potential lung cancer biomarkers that has been described previously [15]. The current project was a substudy and only those with pre-operative samples remaining were selected. This gave a total of 148 lung cancer patients, 68 patients with other intrathoracic tumours and 33 noncancer controls. Demographic features, tumour histology and pathological stage, surgery type, resection margins, smoke exposure, and comorbidity were recorded. Pathological staging was taken to be the gold standard and has been updated to reflect the latest staging guidance for non-small cell lung cancer (NSCLC) [16]. Lung cancer patients were followed for up to 5 yrs and survival assessed using Cancer Intelligence (Bristol, UK) data. The study was approved by the local ethics committee and all patients gave informed consent. $25 \mathrm{OHD}_{3}$ was measured by tandem mass spectrometry at HEFT. DBP was measured by specific ELISA (Immunodiagnostik, Bensheim, Germany).

\section{Assessment of VDR and DBP in lung cancers and normal lung tissue}

Tumour and nontumour lung tissue was obtained from 25 patients undergoing resection at HEFT between 2009 and 2010. After resection, lungs were taken immediately to the pathology department for inflation with $10 \%$ formalin at a constant pressure of $25 \mathrm{cmH}_{2} \mathrm{O}$ via cannulation of the major airway and, once inflated, were immersed in formalin for $24 \mathrm{~h}$. Representative blocks of normal lung distant from the tumour and tumour blocks were selected by a single pathologist for subsequent staining. Both VDR and DBP were stained using the Benchmark XT system with Ultraview technology (Ventana, Tucson, AZ, USA). The primary mouse monoclonal antibodies used were anti-VDR (D-6; Santa Cruz Biotechnology Inc., Santa Cruz, CA, USA) and anti-DBP (A0021; Dako, Ely, UK). Staining with both antibodies involved a 30-min antibody retrieval step followed by $32 \mathrm{~min}$ of antibody incubation. The VDR antibody was diluted 1:100 and the DBP antibody 1:10,000. An additional 4-min haematoxylin counterstain was used in the anti-DBP protocol. The VDR protocol was adapted from that published for lung tissue [6] and the DBP protocol from that published for kidney tissue [17]. Positive controls were kidney tissue (VDR) and liver (DBP); positive staining was determined by a pathologist using standard semiquantitative techniques that grade intensity of staining [18].

\section{Assessment of VDR and DBP in lung cancer cell lines and normal lung tissue}

Cancer cell lines were described in our previous work and cultured as indicated therein [19]. NCI-231 was originally a gift to I. Tachibana from Y. Shimosata (National Cancer Research Institute, Tokyo, Japan) in 2003. A549, NCI-H292 and NCI-H69 were purchased from the American Type Culture Collection (Manassas, VA, USA), and authenticated at source in 2003. Lu65 and Lu99 were purchased from the Riken Bioresource Cell Center (Ibaraki, Japan), and authenticated at source in 2003. HARA was purchased from the Health Sciences Research Resource Center (Tokyo, Japan), again in 2003. All cells were tested prior to the experiments herein for neural cell adhesion molecular expression by flow cytometry (either positive or negative; data not shown) and mycoplasma infection (all negative), as described in our previous work [19].

Cells were lysed in a buffer containing: 1\% Triton X-100; $0.1 \%$ sodium dodecylsulfate (SDS); 1 mM EDTA; $10 \mathrm{mM}$ Tris $/ \mathrm{HCl}$, $\mathrm{pH}$ 7.5; $150 \mathrm{mM}$ sodium chloride; $0.01 \%$ sodium azide; and a protease inhibitor cocktail (Sigma, Poole, UK). The protein concentrations of lysates were determined using the Detergent Compatible Protein Assay (Bio-Rad, Hemel Hempstead, UK) and $45-\mu g$ reducing samples were separated on SDS-polyacrylamide gels. Protein was transferred to polyvinylidene fluroide membranes and probed with chicken anti-DBP, rabbit anti-VDR or mouse anti-tubulin antibodies (all Sigma). For DBP and tubulin blots, the secondary antibodies were IRDye $800 \mathrm{CW}$ conjugated for visualisation using the Odyssey Infrared Imaging System (LI-COR, Lincoln, NE, USA). For VDR blots, the secondary antibody was horseradish peroxidase-conjugated (Thermo Scientific, Erembodegem, Belgium) for visualisation using Pierce ECL chemiluminescence reagents (Thermo Scientific) and Hyperfilm (Amersham Biosciences, Amersham, UK), which was developed using a film processor (Curix 60; AGFA, Brentford, UK).

\section{Statistical analysis}

All analyses were carried out in SPSS version 16.0 (Chicago, IL, USA). Clinical data normality was assessed using the Kolmogorov-Smirnov test (normal, $\mathrm{p}>0.05$ ); parametric data is reported as mean \pm SEM and nonparametric data as median (range). The unpaired t-test was used to compare means of parametric data and the Mann Whitney or Kruskal-Wallis test for nonparametric data between groups. Frequency variables 
were compared using the Chi-squared test. Bonferroni correction for multiple tests was used for these analyses, meaning that unadjusted overall $\mathrm{p}$-value for significance was 0.01. A multivariate Cox regression analysis was carried out for survival of those NSCLC cases with clear resection margins using age, sex, smoke exposure, histological type and cancer stage, plus DBP or vitamin D level as predictors. DBP was assessed in quartiles rather than as a continuous variable. All comparisons of vitamin D took into account season of collection, as described in our previous work [13]. Statistical significance was assumed at $p<0.05$ in the absence of Bonferroni correction.

\section{RESULTS}

\section{Prognostic effect of serum markers of the vitamin $D$ axis}

Characteristics of the patients are shown in table 1 . None was taking prescribed vitamin D supplements when admitted for surgery. There were no significant differences between the two cancer groups (all $\mathrm{p}>0.05)$. Noncancer controls were younger, more likely to be male and had been followed up for fewer years $(\mathrm{p}=0.03, \mathrm{p}<0.01$ and $\mathrm{p}=0.02$, respectively).

The histology of the lung tumours and pathology of the other patient groups are shown in figure 1. Squamous cell carcinomas were the most frequent lung tumour while oesophageal cancers formed the majority of the other cancers. Six patients had small cell lung cancer and were excluded from further analyses. Among the NSCLC cases, pathological stages were distributed as follows: Ia, 27 patients; Ib, 45 patients; IIa, 11 patients; IIb, 10 patients; IIIa, 22 patients; and IIIb, seven patients. In 20 cases, new staging could not be determined from the pathology report due to the level of detail given. Among the other cancers, all oesophageal patients were stage IIa or IIb, all mesothelioma patients were stage II, and of the two lymphoma patients, one was stage II and one stage III.

As expected, cholecalciferol varied with season of collection, although this difference was marginal and unlikely to be of clinical significance (online supplementary material). After adjustment for this, it tended to be higher in lung cancer than noncancerous lung disease, although this was not statistically significant ( 38.5 versus $30.8 \mathrm{ng} \cdot \mathrm{mL}^{-1}, \mathrm{p}=0.06$ ). In other cancers, vitamin $\mathrm{D}$ was lower $\left(15.7 \mathrm{ng} \cdot \mathrm{mL}^{-1}, \mathrm{p}<0.01\right)$. This is shown in figure 2a. Frequencies of the three usual classes of vitamin D level in the lung cancer patients are shown in figure $2 b$. DBP was lower in lung cancer patients than in noncancerous lung disease (33.7 versus $45.5 \mathrm{mg} \cdot \mathrm{dL}^{-1}, \mathrm{p}=0.02$ ) but did not differ from other cancers $\left(35.9 \mathrm{mg} \cdot \mathrm{dL}^{-1}, \mathrm{p}=0.72\right)$. This is also shown in figure 2a. DBP and cholecalciferol did not correlate with one another $(p=0.62)$. Albumin did not vary significantly between groups (both $\mathrm{p}>0.32$ ); there was no significant correlation between this and cholecalciferol $(p=0.72)$ or DBP $(p=0.24)$.

All patients had undergone $\geqslant 12$ months of follow-up at the time of data analysis. 1-yr survival was $79.1 \%$. Of those who died during their follow-up period, the median time to death was 0.93 yrs (range $0-3.54$ yrs); when only cancer-related deaths were selected, mean time to death was 1.04 yrs (range 03.45 yrs). Survival at the mean of covariates, excluding DBP and vitamin $\mathrm{D}$, is shown in figure $3 a$ and substratified for quartiles of DBP in figure $3 \mathrm{~b}$. Stage, age and pack-years smoked were all significant predictors of death $(p=0.039, p=0.005$ and $p=0.009$, respectively), while sex was not $(p=0.96)$. In the all-cause mortality analysis, neither $\mathrm{DBP}$ nor $25 \mathrm{OHD}_{3}$ predicted death (both $\mathrm{p}>0.30$ ). When only deaths secondary to lung cancer were considered, DBP became a predictor $(\mathrm{p}=0.041)$, the odds ratio of death falling to 0.95 (95\% CI 0.91-0.98) for each unit gained in DBP. To put this into context, a lung cancer patient exhibiting DBP levels equivalent to that of our healthy cohort would have an odds ratio for death of 0.59 compared with a patient with the mean DBP level seen in our cohort. Further details of the DBP analyses are shown in table 2; the wide confidence intervals reflect the small numbers of deaths.

Albumin was also assessed as a predictor in order to ascertain whether the DBP effect was specific; albumin was not significant $(p=0.38)$. Cholecalciferol did not predict lung cancer death $(\mathrm{p}=0.52)$.

\section{Assessment of VDR and DBP in lung cancers and normal lung tissue}

In normal lung tissue, VDR was expressed most strongly in bronchial epithelium with lesser staining in pneumocytes

\section{TABLE 1 Characteristics of the patients}

Subjects $\mathrm{n}$
Age yrs
Males
Smoking exposure pack-yrs
Current smokers
Never-smokers
Cancer death
Other death
Follow-up yrs
DBP $\mathrm{mg} \cdot \mathrm{dL} \mathrm{L}^{-1}$
Cholecalciferol $\mathrm{ng} \cdot \mathrm{mL}^{-1}$
Albumin $\mathrm{g} \cdot \mathrm{L}^{-1}$

Data are presented as mean $\pm \mathrm{SE}$, median (range) or $\mathrm{n}(\%)$, unless otherwise stated. DBP: vitamin $\mathrm{D}$ binding protein.
Lung cancer

Other cancer

Noncancer controls

148
$69.7 \pm 1.5$
$57(38.5)$
$50.0(5-120)$
$57(38.5)$
$7(4.7)$
$33(22.3)$
$23(15.5)$
$4.3(1.5-5.3)$
$33.7 \pm 1.5$
$38.5 \pm 1.6$
$37.6 \pm 3.8$

33

$66.6(54-80)$

22 (32.4)

$60.0(30-100)$

9 (13.2)

$3(4.4)$

$4.5(1.8-5.7)$

$35.9 \pm 2.4$

$15.7 \pm 2.0$

33.4 (27.2-39.6)
54.5 (33-88)

$24(72.7)$

$43.3(0-70)$

1 (3.0)

4 (12.1) 


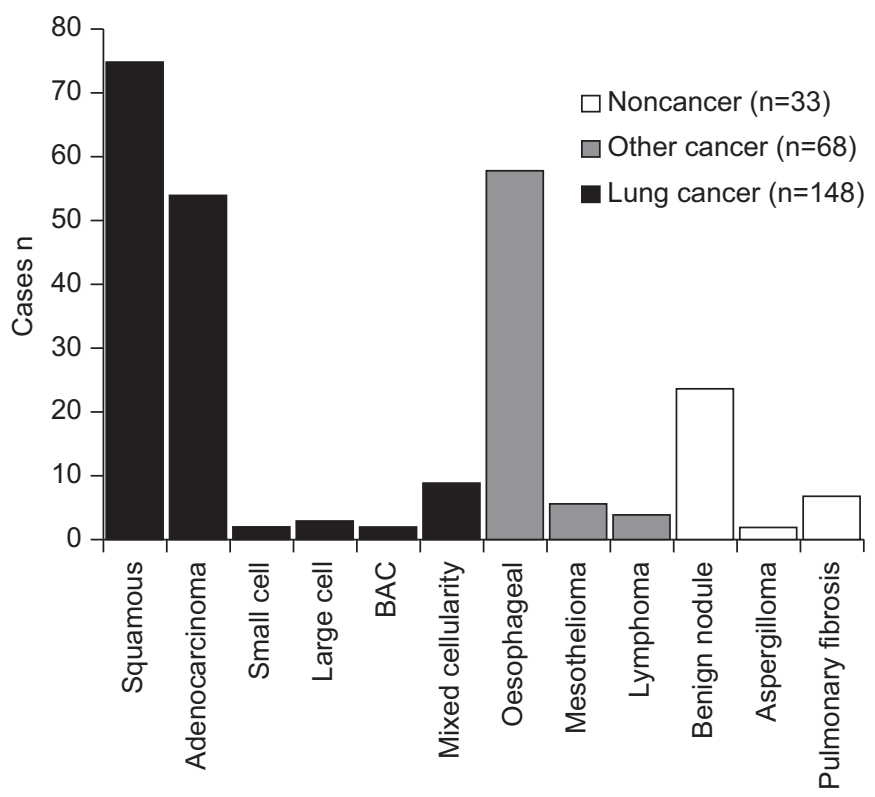

FIGURE 1. Pathological findings in the three patient groups. The majority of the lung cancer cases were either squamous cell carcinomas or adenocarcinomas, with smaller numbers of small cell, large cell, bronchoalveolar cell (BAC) and mixed cellularity tumours. The majority of the other intrathoracic cancers were oesophageal, while the bulk of the noncancer cases were benign nodules.

(fig. 4a and b). Only one tumour did not exhibit VDR expression; however, half exhibited less intense staining than the normal lung tissue from that individual (fig. $4 \mathrm{c}$ and d). In normal lung tissue, DBP was present predominantly in blood and airway secretions with less intense staining in macrophages (fig. 4e and f). In general, tumour tissue only stained positive for DBP in necrotic areas and associated macrophages; elsewhere, it exhibited intensity half that of airway secretions (fig. $4 \mathrm{~g}$ and $\mathrm{h}$ ). $16 \%$ of tumours showed no DBP expression. Consistent with the relatively low expression of VDR and DBP in lung tumours, eight lung cancer cell lines exhibited low or no expression of these proteins by Western blotting compared with positive control blots of four normal lung samples (fig. 5). Normal lung tissue was used a positive control because of the detection of these proteins in lung sections (fig. 4).

\section{DISCUSSION}

We have shown that low serum DBP before surgery may be a predictor of subsequent death from lung cancer and that expression of DBP is either low or absent in lung cancer tissue. This supports a pathogenic role for DBP in lung cancer, which is most likely to centre on its role as a precursor for DBP-MAF, based on its location on macrophages in normal lung and in necrotic areas in tumours. It seems likely that DBP is not produced extensively by lung tissue but diffuses from the blood to airway secretions and tissue fluids, given that little staining was observed in any primary pulmonary cells in the normal lung samples and the Western blots from cell lines showed no expression. This may explain why a serum marker was capable of predicting a lung-specific outcome. Small amounts of DBP expression by normal lung and tumours remains a possibility. Prognostic markers in lung cancer include ERCC1, epidermal growth factor receptor, RRM1 and KRAS, although most of

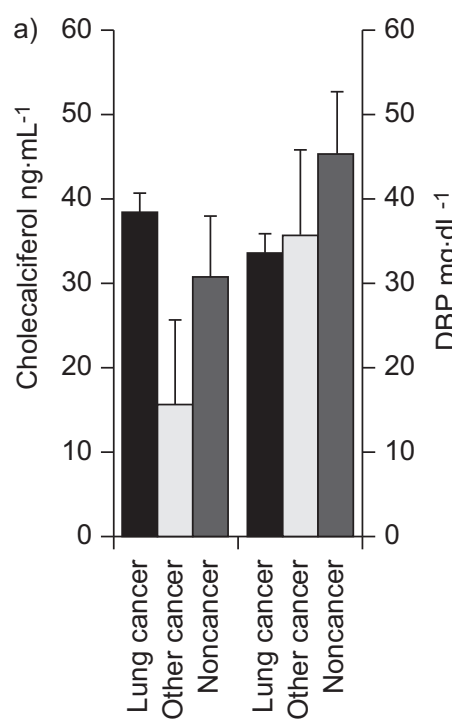

b)

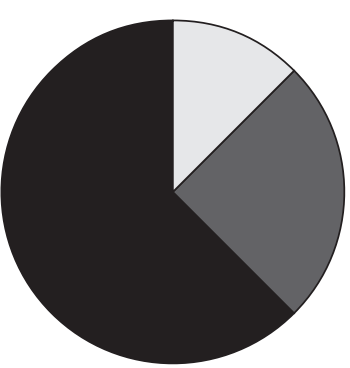

Deficient $\left(<20 \mathrm{ng} \cdot \mathrm{mL}^{-1}\right)$

Insufficient (20-30 ng. $\left.\mathrm{mL}^{-1}\right)$

Sufficient $\left(>30 \mathrm{ng} \cdot \mathrm{mL}^{-1}\right)$

FIGURE 2. Components of the vitamin D axis in cancer and noncancer patients. a) Mean \pm SEM vitamin D (cholecalciferol) and vitamin D binding protein (DBP) levels in the three groups. Vitamin D did not differ between lung cancer and noncancer patients $(p=0.06)$ but was significantly lower in the other intrathoracic malignancies $(p<0.01)$. DBP was lower in lung cancer than noncancer patients $(p=0.02)$ but did not differ from other cancers $(p=0.72)$. b) Clinical categories of vitamin $\mathrm{D}$ level in the lung cancer patients. The majority of lung cancer patients were sufficient in vitamin D.

these are better validated as markers in tumours than circulating blood [20]. A recent review of lung cancer biomarkers noted that many of the studies looking at such biomarkers and survival have been conducted retrospectively on samples collected during clinical trials, such that their role in predicting response to therapy rather than outcome per se is better known [20]. The hazard ratio for the lowest quartile of DBP was similar to that conferred by high levels of circulating cancer cells in a recent study of 101 patients with stage III or IV NSCLC [21].

The link between DBP and lung cancer has not been studied in detail; one study of circulating DBP levels showed no difference between cancer and healthy individuals [22]. However, the techniques for measuring DBP used in this study were much less sensitive than the current ELISA and the study itself was not specific to lung cancer, comprising a total of 100 cases split between lung, prostate and gastrointestinal malignancies. More recently, proteomic work in a mouse model of lung cancer suggested that DBP acts as a disease biomarker [23]. DBP is regulated at a transcriptional level by pro-inflammatory cytokines and steroids [24], and could potentially relate to nutrition and catabolic states, rather like albumin, since it is in the same family of proteins. We did not show any relationship of survival with albumin levels but cannot exclude an epiphenomenon linking DBP to another unmeasured poor prognostic factor influencing our DBP mortality analyses.

Previous work has shown that conversion of DBP to DBP-MAF may be reduced in malignancy due to the action of $\alpha-N$ acetylgalactosaminidase [25]. During tumour invasion, various cells in cancerous tissues produce exo- and endoglycosidases [26], and if the latter enter the bloodstream, they are capable of deglycosylating circulating DBP, a process that appears to 

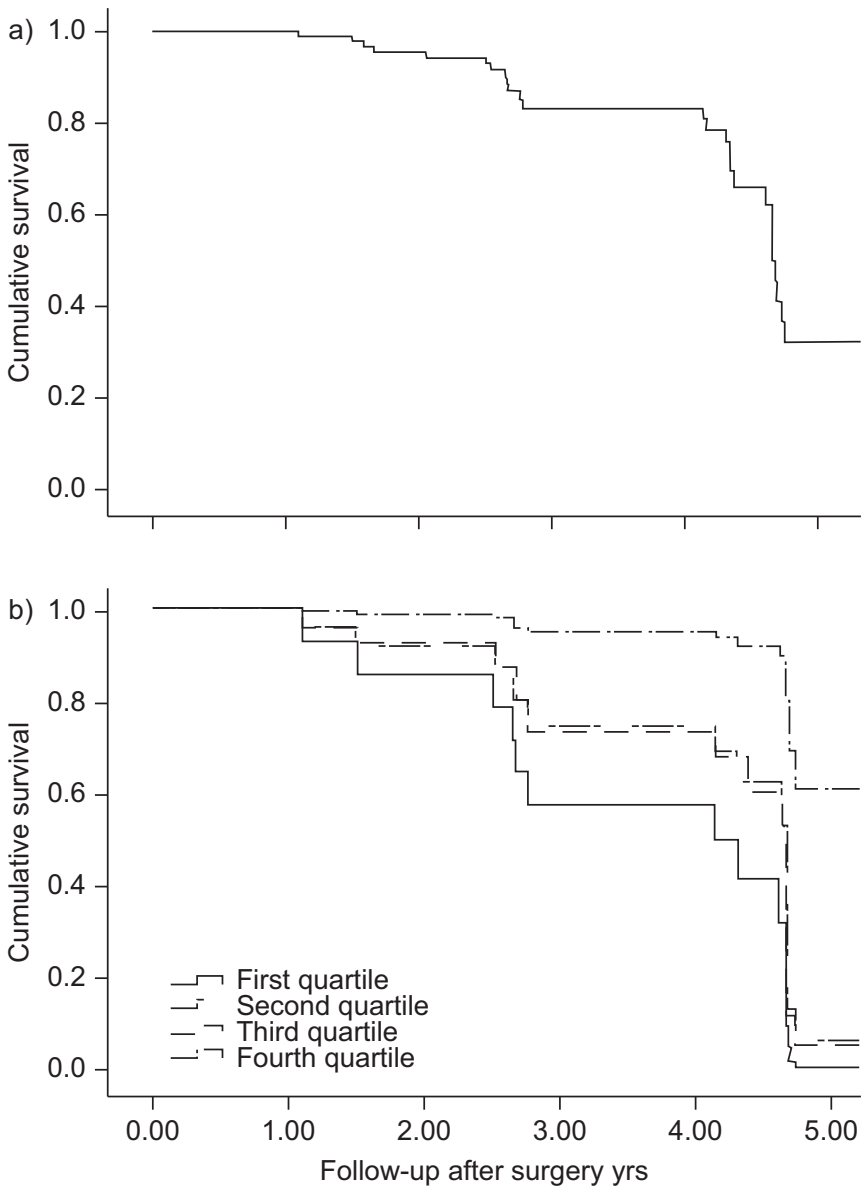

FIGURE 3. Survival in the lung cancer patients. a) Survival from the Cox regression analyses at the mean of all covariates, before the addition of vitamin $D$ binding protein (DBP) or vitamin $D$ to the model. b) Shows survival at the mean of covariates substratified by DBP level.

relate directly to tumour burden in a murine model [27]. Our data show that DBP concentration is low in the blood of lung cancer patients. Thus, even if DBP deglycosylation is not involved, macrophage activation may be lower, adversely affecting prognosis. Augmentation of DBP-MAF has been proposed as adjuvant therapy in surgically resected cancers for these reasons; indeed, in colonic and prostate cancers, DBPMAF immunotherapy used in this way was safe and well

\begin{tabular}{|c|c|c|c|c|}
\hline TABLE 2 & $\begin{array}{l}\text { elationship c } \\
\text { otein (DBP) } \\
\text { e nonsmall }\end{array}$ & $\begin{array}{l}\text { quartiles } \\
\text { o lung c } \\
\text { ell lung }\end{array}$ & $\begin{array}{l}\text { of vitamin } D \text { binc } \\
\text { ncer-specific dea } \\
\text { incer cases }\end{array}$ & $\begin{array}{l}\text { ling } \\
\text { th in }\end{array}$ \\
\hline DBP quartile & DBP $\mathrm{mg} \cdot \mathrm{dL}^{-1}$ & $\begin{array}{c}\text { Deaths }^{\#} \\
\mathrm{n} / \mathrm{N}\end{array}$ & OR' (95\% Cl) & $\mathrm{p}$-value \\
\hline Fourth quartile & $>43.02$ & $3 / 32$ & & \\
\hline Third quartile & $33.25-43.01$ & $9 / 35$ & $5.49(0.62-48.52)$ & 0.125 \\
\hline Second quartile & $19.95-33.24$ & $7 / 31$ & $5.77(0.59-56.64)$ & 0.133 \\
\hline First quartile & $<19.94$ & $7 / 34$ & $10.4(1.03-125.42)$ & 0.044 \\
\hline
\end{tabular}

\#: lung cancer specific; ": for mortality compared with the fourth quartile.
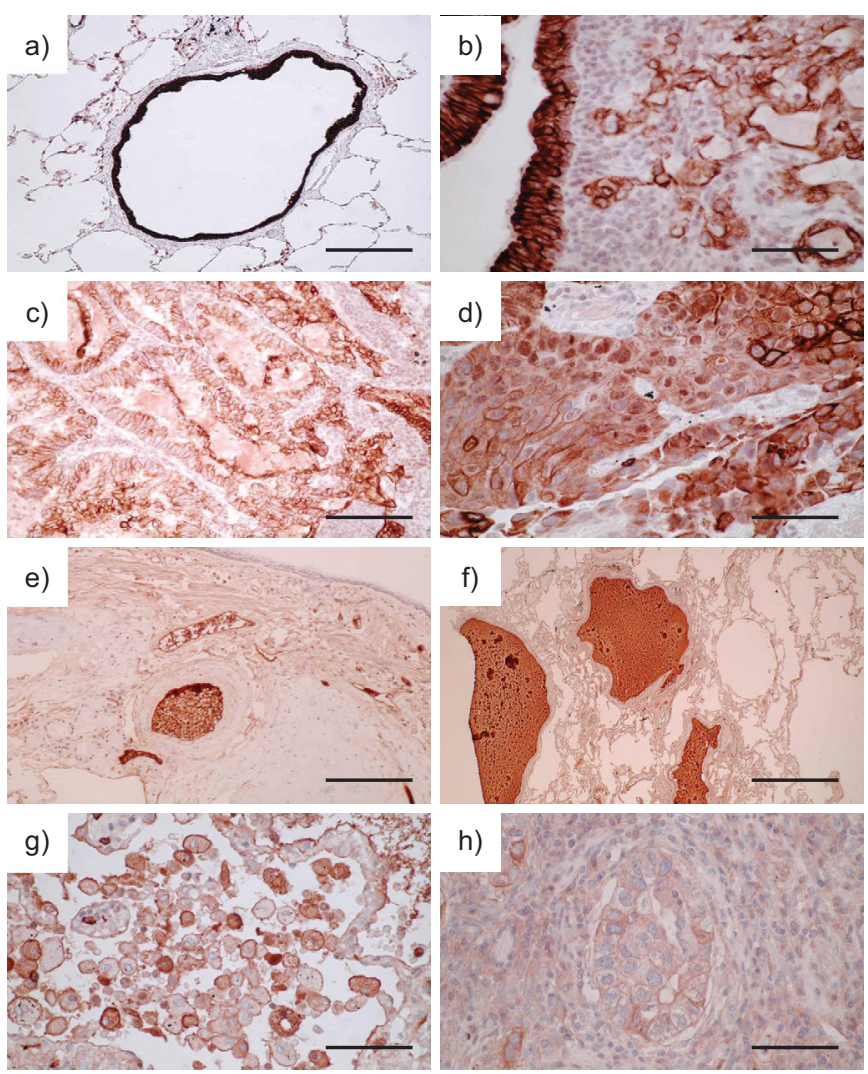

FIGURE 4. Vitamin $D$ receptor (VDR) and vitamin $D$ binding protein (DBP) expression in lung tissue. VDR stains strongly in bronchial epithelium, seen at a) $10 \times$ magnification and more strongly than adjacent tumour tissue when seen at b) $40 \times$. VDR generally exhibited less intense staining in tumour tissue; two tumours are shown at c) $20 \times$ and d) $40 \times$ magnification. DBP is seen in e) blood and f) airway secretions (both $10 \times$ magnification). DBP is seen on g) macrophages and at low intensity in $h$ ) an adenocarcinoma (both $40 \times$ magnification). Scale bars: a, c, e and g) $100 \mu \mathrm{m}$; b) $20 \mu \mathrm{m}$; and d, f and h) $10 \mu \mathrm{m}$.

tolerated in early-phase trials [28, 29]. DBP-MAF has also shown beneficial effects on breast cancer cells in vitro [30]. These concepts require further follow up before trials of DBP-MAF would be appropriate in lung cancer, but provide an exciting new avenue for research. Specifically, a more extensive analysis of the expression of DBP-MAF and the mechanisms of deglycosylation in lung tissue would be required in the future.

Cholecalciferol did not predict outcome in our survival analysis. Few studies have been performed examining vitamin D status specifically in lung cancer. ZHOU et al. [31] investigated the association between surgery season and vitamin $\mathrm{D}$ intake with recurrence-free and overall survival in 456 early-stage NSCLC patients. They concluded that the joint effect of season and intake are associated and higher $25 \mathrm{OHD}_{3}$ levels correlated with improved overall and recurrence-free survival [31]. In our study, levels were higher in summer, although the differences were unlikely to be clinically significant; a specific survival analysis according to season of surgery was not carried out for this reason. As the main source of vitamin D is synthesis in the skin following sun exposure, several studies have investigated seasonal and geographical variation in cancer risk and survival $[32,33]$. One such study investigated the impact of season of 


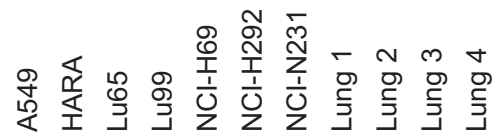

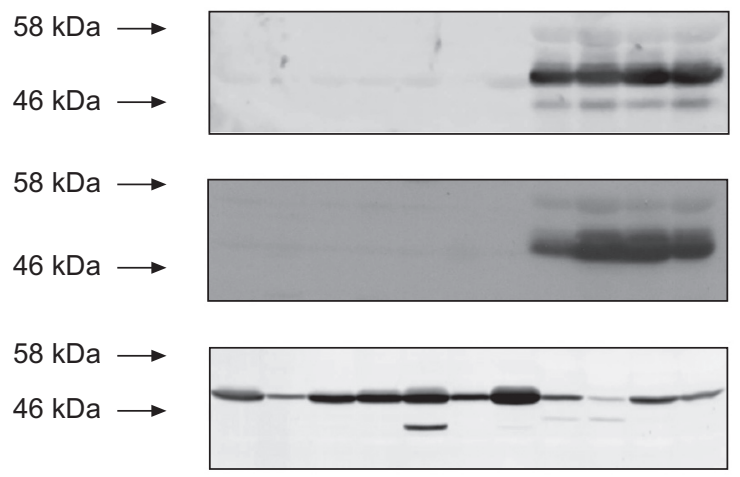

DBP

VDR

Tubulin

FIGURE 5. Vitamin D binding protein (DBP) and vitamin D receptor (VDR) expression assessed by Western blotting in lung cancer cell line and lung tissue lysates. The blots show DBP, VDR and tubulin (control) expression in lung cancer cell lines (A549 to NCl-N231) and normal lung tissue samples (lung 1-4). DBP and VDR were universally expressed by whole lung lysates. In the cancer cell lines, DBP was expressed very weakly in some lines and absent from most, while VDR was not expressed

diagnosis and residential region on the risk of death from lung cancer in Norwegian lung cancer patients [34]. The results suggested that vitamin D status at lung cancer diagnosis is of prognostic value and that cancer mortality decreases with increasing sun exposure [34]. Our results are in direct contrast to these studies, perhaps because of differences in the study cohorts. First, $<20 \%$ of our patients were deficient in vitamin D (fig. 2b). Secondly, we showed that most tumours exhibited lower VDR expression than normal epithelial tissue. This means that the tumours would be less responsive to vitamin $D$, thus preventing its antitumour activities. Our immunohistochemistry results concur with a larger study on the expression of VDR in normal, premalignant and malignant bronchial tissue [6]. Furthermore, they are also consistent with genetic epidemiology work that shows that $V D R$ polymorphisms that lead to reduced VDR function are associated with malignancy in general [35]. This observation echoes smaller lung cancer studies that have shown that the VDR FokI polymorphism is associated with worse survival in NSCLC $[36,37]$ while the TaqI polymorphism influences lung cancer risk, its effect being modified by age, sex and smoking habit [38]. It is also possible that unmeasured confounders, such as body weight, could have had an influence on our results.

Our study is limited to surgically resected cases, which led to relatively small numbers for the survival analyses; nevertheless, the cohort remains competitive in the field for its size and degree of characterisation. The proportion of female patients is higher than the average and many cases were quite advanced on pathological staging (stage IIIa or b), which may reduce the ability of the results to be generalised to other patient cohorts. We did not formally account for adjuvant therapy use in our analyses since only three patients received it; given the low numbers, we felt it would be uninformative to do so but acknowledge that there is a small chance this could affect results. The study is also the first to report DBP immunohistochemistry in the lung. We were unable to confirm the location of DBP on macrophages by colocalisation of DBP and CD68 stains due to a high level of background staining in the dually stained images (data not shown, available on request), although many of the slides show morphologically that the staining is on this cell type. We corrected our analyses for multiple tests and acknowledge that it is only the unadjusted p-value for DBP that reaches significance, since four quartiles were tested. However, given the marked difference in survival in this group and the functional data we present to support our findings, there remains potential for clinical significance.

In summary, we have shown that low circulating DBP concentration may predict poor prognosis in NSCLC, which we hypothesise is because of its role as a precursor to DBPMAF. The results require independent replication and assessment in larger cohorts before we can be certain of the validity of DBP as a prognostic marker. If our results are validated by other groups, further research to determine whether DBP-MAF may be a useful therapy in the future could be warranted.

\section{SUPPORT STATEMENT}

A.M. Turner is supported by the West Midlands Chest Fund and Cancer Research UK. L. McGowan is supported by the Society for Endocrinology. M.G. Tomlinson is supported by a Senior Fellowship from the British Heart Foundation. F. Berditechevski is supported by Cancer Research UK. B. Naidu is supported by The Health Foundation and the Midlands Lung Tissue Collaborative. No funder had any contribution to the design, conduct or analysis of the work.

\section{STATEMENT OF INTEREST}

None declared.

\section{ACKNOWLEDGEMENTS}

The authors would like to thank staff in the Dept of Thoracic Surgery (Heart of England NHS Trust, Birmingham, UK) who contributed to tissue collection. We are also grateful to J. Yang and V. Novitskaya (Dept of Cancer Sciences, University of Birmingham, Birmingham) for their help with culture of lung cell lines.

\section{REFERENCES}

1 Holick MF. Evolution and function of vitamin D. Recent Results Cancer Res 2003; 164: 3-28.

2 Giovannucci E. The epidemiology of vitamin D and cancer incidence and mortality: a review (United States). Cancer Causes Control 2005; 16: 83-95.

3 Nakagawa K, Sasaki Y, Kato S, et al. 22-Oxa-1 $\alpha, 25$-dihydroxyvitamin $D_{3}$ inhibits metastasis and angiogenesis in lung cancer. Carcinogenesis 2005; 26: 1044-1054.

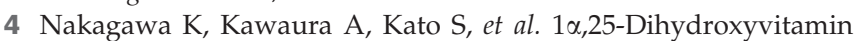
$\mathrm{D}_{3}$ is a preventive factor in the metastasis of lung cancer. Carcinogenesis 2005; 26: 429-440.

5 Chishimba L, Thickett DR, Stockley RA, et al. The vitamin D axis in the lung: a key role for vitamin D-binding protein. Thorax 2010; 65: 456-462.

6 Menezes RJ, Cheney RT, Husain A, et al. Vitamin D receptor expression in normal, premalignant, and malignant human lung tissue. Cancer Epidemiol Biomarkers Prev 2008; 17: 1104-1110.

7 Swamy N, Head JF, Weitz D, et al. Biochemical and preliminary crystallographic characterization of the vitamin D sterol- and actin-binding by human vitamin D-binding protein. Arch Biochem Biophys 2002; 402: 14-23. 
8 McLeod JF, Cooke NE. The vitamin D-binding protein, alphafetoprotein, albumin multigene family: detection of transcripts in multiple tissues. J Biol Chem 1989; 264: 21760-21769.

9 Kew RR, Sibug MA, Liuzzo JP, et al. Localization and quantitation of the vitamin D binding protein (Gc-globulin) in human neutrophils. Blood 1993; 82: 274-283.

10 Yamamoto $\mathrm{N}$, Homma $\mathrm{S}$. Vitamin $\mathrm{D}_{3}$ binding protein (groupspecific component) is a precursor for the macrophage-activating signal factor from lysophosphatidylcholine-treated lymphocytes. Proc Natl Acad Sci USA 1991; 88: 8539-8543.

11 Mantovani A, Sica A. Macrophages, innate immunity and cancer: balance, tolerance, and diversity. Curr Opin Immunol 2010; 22: 231-237.

12 Ohri CM, Shikotra A, Green RH, et al. Macrophages within NSCLC tumour islets are predominantly of a cytotoxic M1 phenotype associated with extended survival. Eur Respir J 2009; 33: 118-126.

13 Wood AM, Bassford C, Webster D, et al. Vitamin D-binding protein contributes to COPD by activation of alveolar macrophages. Thorax 2011; 66: 205-210.

14 Yokomura K, Suda T, Sasaki S, et al. Increased expression of the 25hydroxyvitamin $\mathrm{D}_{3}-1 \alpha$-hydroxylase gene in alveolar macrophages of patients with lung cancer. J Clin Endocrinol Metab 2003; 88: 5704-5709.

15 Rathinam S, Alzetani A, Starczynski J, et al. Confounding effects of benign lung diseases on non-small cell lung cancer serum biomarker discovery. Clin Proteomics 2009; 5: 148-155.

16 Nair A, Klusmann MJ, Jogeesvaran $\mathrm{KH}$, et al. Revisions to the TNM staging of non-small cell lung cancer: rationale, clinicoradiologic implications, and persistent limitations. Radiographics 2011; 31: 215-238.

17 Wilmer MJ, Christensen EI, van den Heuvel LP, et al. Urinary protein excretion pattern and renal expression of megalin and cubilin in nephropathic cystinosis. Am J Kidney Dis 2008; 51: 893-903.

18 Cregger M, Berger AJ, Rimm DL. Immunohistochemistry and quantitative analysis of protein expression. Arch Pathol Lab Med 2006; 130: 1026-1030.

19 Funakoshi T, Tachibana I, Hoshida Y, et al. Expression of tetraspanins in human lung cancer cells: frequent downregulation of CD9 and its contribution to cell motility in small cell lung cancer. Oncogene 2003; 22: 674-687.

20 Martin Ureste M, Girones Sarrio R, Montalar Salcedo J. Biomarkers in bronchopulmonary cancer. Clin Transl Oncol 2010; 12: 92-99.

21 Krebs MG, Sloane R, Priest L, et al. Evaluation and prognostic significance of circulating tumor cells in patients with non-smallcell lung cancer. J Clin Oncol 2012; 30: 525-532.

22 Rostenberg I, Rico R, Penaloza R. Gc globulin and prealbumin serum levels in patients with cancer and benign inflammatory diseases and in asymptomatic smokers. J Natl Cancer Inst 1979; 62: 299-300.
23 Chatterji B, Borlak J. Serum proteomics of lung adenocarcinomas induced by targeted overexpression of c-raf in alveolar epithelium identifies candidate biomarkers. Proteomics 2007; 7: 3980-3991.

24 Guha C, Osawa M, Werner PA, et al. Regulation of human Gc (vitamin D-binding) protein levels: hormonal and cytokine control of gene expression in vitro. Hepatology 1995; 21: 1675-1681.

25 Yamamoto N, Naraparaju VR, Asbell SO. Deglycosylation of serum vitamin $\mathrm{D}_{3}$-binding protein leads to immunosuppression in cancer patients. Cancer Res 1996; 56: 2827-2831.

26 Woynarowska B, Wikiel H, Bernacki RJ. Human ovarian carcinoma $\beta-N$-acetylglucosaminidase isoenzymes and their role in extracellular matrix degradation. Cancer Res 1989; 49: 5598-5604.

27 Yamamoto N, Naraparaju VR, Urade M. Prognostic utility of serum $\alpha$-N-acetylgalactosaminidase and immunosuppression resulted from deglycosylation of serum Gc protein in oral cancer patients. Cancer Res 1997; 57: 295-299.

28 Yamamoto N, Suyama H, Nakazato H, et al. Immunotherapy of metastatic colorectal cancer with vitamin D-binding proteinderived macrophage-activating factor, GcMAF. Cancer Immunol Immunother 2008; 57: 1007-1016.

29 Yamamoto N, Suyama H. Immunotherapy for prostate cancer with gc protein-derived macrophage-activating factor, GcMAF. Transl Oncol 2008; 1: 65-72.

30 Pacini S, Punzi T, Morucci G, et al. Effects of vitamin D-binding protein-derived macrophage-activating factor on human breast cancer cells. Anticancer Res 2012; 32: 45-52.

31 Zhou W, Heist RS, Liu G, et al. Circulating 25-hydroxyvitamin D levels predict survival in early-stage non-small-cell lung cancer patients. J Clin Oncol 2007; 25: 479-485.

32 Robsahm TE, Tretli S, Dahlback A, et al. Vitamin $\mathrm{D}_{3}$ from sunlight may improve the prognosis of breast-, colon- and prostate cancer (Norway). Cancer Causes Control 2004; 15: 149-158.

33 Lim HS, Roychoudhuri R, Peto J, et al. Cancer survival is dependent on season of diagnosis and sunlight exposure. Int $J$ Cancer 2006; 119: 1530-1536.

34 Porojnicu A, Robsahm TE, Berg JP, et al. Season of diagnosis is a predictor of cancer survival. Sun-induced vitamin D may be involved: a possible role of sun-induced vitamin D. J Steroid Biochem Mol Biol 2007; 103: 675-678.

35 Raimondi S, Johansson H, Maisonneuve P, et al. Review and metaanalysis on vitamin $\mathrm{D}$ receptor polymorphisms and cancer risk. Carcinogenesis 2009; 30: 1170-1180.

36 Zhou W, Heist RS, Liu G, et al. Polymorphisms of vitamin D receptor and survival in early-stage non-small cell lung cancer patients. Cancer Epidemiol Biomarkers Prev 2006; 15: 2239-2245.

37 Heist RS, Zhou W, Wang Z, et al. Circulating 25-hydroxyvitamin $\mathrm{D}$, VDR polymorphisms, and survival in advanced non-small-cell lung cancer. J Clin Oncol 2008; 26: 5596-5602.

38 Dogan I, Onen HI, Yurdakul AS, et al. Polymorphisms in the vitamin D receptor gene and risk of lung cancer. Med Sci Monit 2009; 15: BR232-BR242. 